\title{
Cálculo Diferencial e Integral e Geometria Analítica e Álgebra Linear na educação a distância
}

\section{Differential and Integral Calculus and Analytical Geometry and Linear Algebra in distance learning}

\author{
Aline Fornari ${ }^{1}$. Claudete Cargnin ${ }^{2}$. Priscila Pigatto Gasparin ${ }^{3}$. \\ Everton Coimbra de Araújo ${ }^{4}$
}

\begin{abstract}
Resumo: O presente artigo apresenta reflexões sobre a oferta das disciplinas de Cálculo Diferencial e Integral I e de Geometria Analítica e Álgebra Linear na modalidade à distância, pela UTFPR, a qual teve início no ano de 2014. Os dados foram obtidos por meio de questionários aplicados aos alunos ao final de cada um dos semestres letivos, em diversos câmpus onde o projeto foi implantado. Os dados indicam que, apesar das dificuldades inerentes ao conteúdo específico e da modalidade, os alunos estão cientes de que a Educação a Distância exige autodisciplina, responsabilidade e motivação, uma vez que preconiza a autonomia discente frente à sua aprendizagem. Os alunos que estudam todo o conteúdo, participam das monitorias e atendimentos e realizam todas as atividades, têm tido maior aprovação nas disciplinas. Frente às análises realizadas, houve alterações no projeto e no material disponibilizado, visando à melhoria contínua no processo de ensino e a aprendizagem.
\end{abstract}

Palavras-chave: Ensino superior. Ensino a distância. Ambiente virtual de aprendizagem. Ensino de matemática.

\begin{abstract}
This paper presents reflections on the provision of disciplines of Differential and Integral Calculus I and Analytic Geometry and Linear Algebra in distance mode, by UTFPR, which began in the year 2014. We collected the data through questionnaires given to students at the end of each of the semesters in several campuses where the project was implemented. The data indicate that, despite the difficulties inherent in the specific content and form, students are aware that distance education requires self-discipline, responsibility and motivation, since it calls for student autonomy in learning. Students, who study all the content, participate in tutoring and perform all activities, have had greater approval in the disciplines. Arising from the analyses, there were changes in design and available material, aiming at continuous improvement in the teaching and learning.
\end{abstract}

Keywords: Higher education. Distance learning. Virtual learning environment. Mathematics learning.

\footnotetext{
${ }^{1}$ Instituto Federal do Paraná (IFPR), Curitiba, PR, Brasil. E-mail: < fornarialine@gmail.com>.

${ }^{2}$ Universidade Tecnológica Federal do Paraná (UTFPR), Departamento de Matemática e Estatística (DAMAT), Medianeira, PR, Brasil.

${ }^{3}$ UTFPR, Departamento de Matemática e Estatística (DAMAT), Campo Mourão, PR, Brasil.

${ }^{4}$ UTFPR, Departamento Acadêmico de Computação, Medianeira, PR, Brasil.
} 


\section{Introdução}

O avanço da tecnologia tem proporcionado acesso irrestrito às informações, possibilitando aquisição de conhecimento de forma mais equitativa. Com isso, a tecnologia tem motivado mudanças significativas na educação, como a propagação da Educação a Distância (EaD). Nesta modalidade de ensino, é essencial a utilização das Tecnologias de Informação e Comunicação (TIC) entre alunos e professores, que podem estar separados geograficamente (DALFOVO et al., 2015).

Nesse sentido, os Ambientes Virtuais de Ensino e Aprendizagem (AVEA) têm proporcionado o desenvolvimento e o uso de recursos e metodologias que aprimoram a autonomia dos estudantes. Além disso, podem ser vistos como espaços de aprendizagem nos quais se ampliam as possibilidades de construção de conhecimento pelo fato de promoverem e fomentarem o questionamento e a problematização, contribuindo, assim, para o processo contínuo de virtualização e atualização, inerentes à reflexão. (RICCIO, 2010).

A Universidade Tecnológica Federal do Paraná (UTFPR) utiliza o ambiente virtual de ensino e aprendizagem Modular Object-Oriented Dynamic Learning Environment (MOODLE), que é uma plataforma gratuita e com código aberto. Sendo assim, cursos ou disciplinas podem ser construídos, padronizados e flexibilizados pelos professores e administradores, de acordo com a necessidade educacional da Instituição. Enquanto ambiente de ensino e aprendizagem o MOODLE oferece facilidades para a inserção de links para vídeo-aulas, conteúdo, por meio de livros, atividades como envio e preenchimento de tarefas, elaboração de questionários e ferramentas colaborativas, como o Wiki. A aprendizagem, por meio desta plataforma, está diretamente ligada à metodologia adotada para a criação e disponibilização dos conteúdos (recursos), atividades e interação entre professor e alunos e alunos com alunos.

O ambiente virtual tem por objetivo auxiliar os educadores a criar cursos on-line com foco na interação e na construção colaborativa do conteúdo, na evolução contínua de uma abordagem construtivista (ROSA; OREY, 2013). Ainda nesse sentido, o MOODLE foi criado com a filosofia da pedagogia do Construcionismo Social, fundamentado na ideia de que as pessoas aprendem melhor quando engajadas em um processo social de construção do conhecimento, com o intuito de construir alguma coisa para outros. (IVASHITA; COELHO, 2009).

A pesquisa aqui apresentada teve o intuito de discutir os resultados de um ano de implantação das disciplinas de Cálculo Diferencial e Integral I (CDI I) e Geometria Analítica e Álgebra Linear (GAAL) no ano letivo de 2014 na modalidade a distância, a partir dos questionários respondidos ao final de cada semestre por um grupo determinado de alunos que cursaram as disciplinas de CDI I e GAAL em vários campi da Universidade. Nossa intenção é debater as seguintes questões: como oferecer cursos eficazes na modalidade EaD? Do que precisam os estudantes para aprenderem nessa modalidade de ensino? Apresentamos os dados levantados e as ações tomadas a fim de reverter as dificuldades percebidas. Nesse artigo, estamos considerando que, se houve aprendizagem do conteúdo específico, o aluno foi capaz de obter aprovação, embora estejamos cientes de que é possível aprender e não ser aprovado. Entretanto, consideramos que essa última possibilidade deve-se a fatores alheios ao que pretendemos abordar nesse trabalho.

Os participantes eram alunos que não obtiveram êxito quando cursaram as referidas disciplinas presencialmente e, naquele ano, as cursavam na modalidade semipresencial, por meio 
do ambiente virtual de ensino e aprendizagem MOODLE. A identificação se deu por meio de uma pesquisa qualitativa e quantitativa, que permitiu a realização de uma análise sobre os resultados de um ano de implantação das disciplinas, possibilitando evidenciar as percepções e perspectivas de alunos sobre a $\mathrm{EaD}$ como alternativa para disciplinas em que há muitos alunos não aprovados na modalidade presencial.

\section{Universidade Tecnológica Federal do Paraná e EaD}

As oportunidades de aprendizagem implicam na criação de meios pelos quais elas poderão acontecer efetivamente, e no caso da Educação a Distância os principais meios a serem considerados são: comprometimento e responsabilidade do aluno, orientação e apoio dos professores, a utilização compartilhada de métodos e meios de transmissão das informações e o respeito às diferenças individuais com a utilização de métodos capazes de respeitar o ritmo da aprendizagem de cada estudante. (MUGNOL, 2009).

A EaD tem a premissa de sanar dificuldades relacionadas à capacitação e à educação da população, em virtude das problemáticas existentes quanto à acessibilidade das pessoas aos locais de educação presencial; utiliza TIC e mídias educativas como pilares para seu desenvolvimento, pois sem elas dificilmente gestores e docentes poderiam promover uma educação de qualidade a um grande número de pessoas. (MORÉ et al., 2010).

Justamente para atender maior número de estudantes é que a Universidade Tecnológica Federal do Paraná começou a trazer para o ensino presencial algumas disciplinas na modalidade semipresencial $(\mathrm{EaD})^{5}$, nas quais o aluno comparece apenas para receber instruções iniciais e fazer as avaliações regimentais. As demais atividades, como conteúdo e tarefas, são realizadas por meio do MOODLE. Em parte, essa inovação foi devido ao conhecido fato que CDI I e GAAL são disciplinas com alto índice de reprovação em todas as instituições que as oferecem, e, devido a isso, sempre há grande número de estudantes sem vaga. A inserção da modalidade semipresencial abranda esse problema e, ainda, reduz a necessidade de contratação de docentes exclusivamente para atender turmas especiais.

Teixeira e Pereira (2012) e Santos e Borges (1993), afirmam que as disciplinas de matemática para os cursos de Ciências Exatas Aplicadas vêm se configurando, ao longo do tempo, nas Instituições de Ensino Superior do país, como as que mais reprovam, e consequentemente as que causam o maior número de desistência. Ainda segundo os autores, existem alguns fatores que contribuem para estes problemas:

- Deficiência de conhecimentos básicos de matemática, originários do ensino fundamental e médio;

- $\quad$ Pouco tempo dedicado ao estudo da disciplina;

- $\quad$ O estudante não tem o hábito de procurar o professor ou o serviço de monitoria, fora do horário de aula, para tirar dúvidas;

\footnotetext{
${ }^{5}$ Nesse artigo, consideramos uma disciplina na qual apenas as instruções iniciais e as provas regimentais como uma disciplina na modalidade EaD.
} 
- $\quad$ O aluno não se identifica com o curso;

- Dificuldade cognitiva do aluno de aprender conteúdos da disciplina;

- A metodologia do professor utilizada em sala de aula não é adequada;

- O professor é rigoroso nas correções das avaliações;

- $\quad$ O número excessivo de alunos em sala de aula.

Corroborando com estas informações, Silva (2008) argumenta que os discentes, ao ingressarem em cursos de nível superior, trazem expectativas inerentes às suas formações básicas, aqueles que no ensino médio conseguiam boas notas em Matemática acabam levando para a universidade a esperança de que o curso com a disciplina de CDI I não represente grandes obstáculos para o seu aprendizado. Entretanto, ao se depararem com questões globais envolvendo os temas anteriormente estudados, em geral abordados isoladamente, acrescidas de novas ideias impactantes como o infinito, as aproximações, a continuidade, a incomensurabilidade, quase sempre veem frustradas suas expectativas iniciais.

Ainda nesse sentido, existem diversos problemas nos cursos iniciais universitários, dentre eles destacam-se: os absurdos índices de abandono e insucesso que afastam os estudantes, de forma permanente; dificuldades de adaptação dos estudantes ao que se ensina na universidade, aos seus processos de instrução e às suas expectativas de aprendizagem. (PALIS, 2010).

Percebe-se ainda que o insucesso dos estudantes está relacionado com a não adequação dos conteúdos que compõem os programas das disciplinas de Cálculo à realidade dos discentes e às necessidades do sistema social, cultural e econômico, com uma metodologia que, em geral, prioriza operações, técnicas e repetição de algoritmos, entre outros fatores. (ALMEIDA; FATORI; SOUZA, 2007; WISLAND; FREITAS; ISHIDA, 2014).

Almeida, Fatori e Souza (2007) destacam ainda outro fator que tem contribuído com a desmotivação dos estudantes, levando à evasão. Segundo as autoras, de maneira geral, nas aulas de Cálculo, os conteúdos são apresentados aos estudantes como um saber já construído, sem lugar para a intuição, experimentação ou descoberta, e perante o qual não é possível a argumentação. Os conceitos são apresentados aos alunos, na maioria das vezes, já formalizados, não decorrentes das suas ações e da reflexão sobre eles, dando-se quase nenhum tempo aos alunos para sentirem a formalização como algo natural e necessário à comunicação de processos e resultados.

Com base nestas informações, Palis (2010, p. 1) expõe a preocupação dos professores e das Instituições de Ensino Superior com a aprendizagem dos novos estudantes:

Como acolher e orientar a aprendizagem dos estudantes que ingressam nos cursos universitários iniciais de matemática, requeridos para estudos nas áreas de engenharia, ciências e matemática, é algo que persiste como um desafio para nós e para diversas universidades pelo mundo. A transição matemática ensino médio-superior na área técnico científica tem sido objeto de preocupação internacional e se configura como um desafio para professores e uma barreira para alunos.

Com relação aos índices de reprovação, falta de vagas para matrícula de alunos repetentes e as dificuldades enfrentadas pelos alunos e professores nas disciplinas de CDI I e GAAL, a UTFPR iniciou a oferta destas disciplinas no primeiro semestre de 2014, com adesão dos campi 
de: Apucarana, Campo Mourão, Cornélio Procópio, Curitiba, Francisco Beltrão, Guarapuava, Londrina e Medianeira. Estes campi, além de ofertarem as disciplinas, fizeram parte da primeira comissão responsável pela elaboração do conteúdo e atividades que deveriam ser disponibilizadas aos estudantes, que, para se inscreverem, não poderiam ter sido reprovados por falta nas referidas disciplinas. Esse trabalho de preparação iniciou-se ainda em 2013.

Sendo assim, os dados analisados no presente artigo são compilações dos questionários respondidos no final do primeiro e segundo semestres letivos de 2014, por cursistas dos campi acima citados, num total de 225 (duzentos e vinte e cinco) participantes (que responderam aos questionários), os quais fazem parte de cursos de graduação na modalidade presencial e que cursam disciplinas em EaD ofertadas pela UTFPR, e utilizam a plataforma MOODLE. O objetivo é realizar uma reflexão sobre os resultados de um ano de implantação das disciplinas de CDI I e GAAL na EaD, como alternativa para disciplinas na qual há muitos alunos não aprovados na modalidade presencial, por meio de uma pesquisa quantitativa e qualitativa.

No ano letivo de 2014 haviam 2409 (dois mil, quatrocentos e nove) matriculados nas duas disciplinas em discussão, apenas no sistema UTFPR (compreende a sede e seus 13 câmpus). Esse número mostra a importância de se discutir alternativas e possibilidades para o ensino da Matemática, e, em particular, do CDI I e GAAL.

Aguiar et al. (2013) afirmam que a pesquisa quantitativa busca magnitude das causas dos fenômenos sociais, sem interesse pela dimensão subjetiva e utiliza instrumentos controlados; assume uma realidade estática. Já os métodos qualitativos devem ser utilizados quando o objeto de estudo não é bem claro. Estes, por proporcionar o surgimento de novos dados, possibilitando ir a fundo ao significado e, de conhecer a perspectiva do sujeito, são aptos para descobrir novos nexos e explicar significados.

As pesquisas qualitativas e quantitativas oferecem novas perspectivas, mas não necessariamente perspectivas opostas. Sendo assim, elementos de ambas as abordagens podem ser usados conjuntamente em estudos mistos, para fornecer mais informações do que poderia se obter utilizando apenas um dos métodos. (MORESI, 2003).

O questionário foi o procedimento metodológico utilizado para o levantamento de dados da pesquisa. Segundo Gil (2008), o questionário pode ser entendido como a técnica de investigação composta por um conjunto de questões que são submetidas a pessoas com o propósito de obter informações sobre conhecimentos, crenças, valores, interesses, expectativas, comportamentos, entre outros.

Com base nestas informações, o questionário utilizado continha 42 questões ao total. Este questionário foi disponibilizado aos alunos no encerramento das disciplinas, com o intuito de identificar o perfil/comportamento dos alunos, bem como identificar possíveis dificuldades relacionadas às disciplinas. Para o desenvolvimento desta pesquisa, foram utilizadas apenas 12 questões, entre perguntas abertas e fechadas, as quais se referiam ao modo de aprender do aluno, avaliação sobre o material didático, avaliação sobre os horários de monitoria, e as principais dificuldades na comunicação entre aluno/professor/monitor.

"Os questionários, na maioria das vezes, são propostos por escrito aos respondentes. Costumam, nesse caso, ser designados como questionários autoaplicados”. (GIL, 2008, p. 121). Os questionários foram disponibilizados aos estudantes ao final das disciplinas, por meio da plataforma MOODLE, com questões abertas e também com questões com alternativas de respostas. Embora tenham sido convidados a responderem, fazê-lo não era obrigatório. Desta maneira, os dados disponíveis foram obtidos por meio de respostas de alunos voluntários. 
Sendo assim, na análise, o pesquisador encontra maiores detalhes sobre os dados referentes ao trabalho estatístico, a fim de conseguir respostas aos seus questionamentos, procurando estabelecer as relações necessárias entre os dados obtidos e as hipóteses formuladas. Desta maneira, são comprovadas ou refutadas, mediante a análise (LAKATOS; MARCONI, 2003).

Assim, o processo de análise dos dados envolve diversos procedimentos, entre eles estão: a tabulação dos dados, os cálculos estatísticos e a codificação das respostas. $\mathrm{Na}$ análise, ocorre a interpretação dos dados, estabelecendo a ligação entre os resultados obtidos com outros já conhecidos de estudos realizados anteriormente. (GIL, 2002).

Com base nestas informações, buscou-se identificar, em cada relato, as diferentes percepções em relação à implantação das disciplinas ofertadas na modalidade a distância e também quanto aos desafios encontrados nas disciplinas de GAAL e CDI I como alternativa para onde há muitos alunos não aprovados na modalidade presencial. Desta maneira, os relatos foram divididos em grupos pelo grau de semelhança entre as respostas, que são apresentadas por meio de gráficos e relatos, obtidos pela pesquisa.

\section{Apresentação e discussão dos dados}

Os alunos que fazem a opção em matricular-se nas disciplinas ofertadas na modalidade semipresencial via plataforma MOODLE realizam suas matrículas pelo sistema acadêmico da UTFPR, regra válida para as demais disciplinas requeridas para matrícula do aluno no âmbito da instituição. Ao iniciar o semestre, os professores responsáveis pelas disciplinas de CDI I e GAAL a distância fazem um encontro presencial com os estudantes para repassar as informações referentes ao uso da plataforma, por exemplo: como acessar o conteúdo, como enviar mensagem para o professor ou monitor para esclarecimentos de dúvidas, calendário das avaliações e horários para atendimentos on-line e presencial.

Para avaliar o progresso dos estudantes, são aplicadas listas de exercícios e questionários, atividades que devem ser realizadas via plataforma, e provas presenciais. Além disso, os professores procuram conversar com os alunos motivando-os a não desistirem e a realizarem as atividades planejadas, as quais contribuem para a aquisição do conhecimento matemático e, consequentemente, preparam para as provas presenciais.

Ao iniciar o acesso à plataforma, os alunos respondem um questionário referente à expectativa de cursar a disciplina na modalidade semipresencial e ao final do semestre eles respondem outro questionário avaliando a disciplina cursada.

Garcia e Direne (2013) argumentam que, com base nestas informações, os professores devem transmitir motivação aos seus alunos para iniciar seus estudos em um processo de ensino diferente do tradicional. Desta maneira, é importante destacar que os estudantes, em muitos casos, estão acostumados à forma tradicional de aprendizagem. Por isso, é provável que ações que envolvem uma mudança no processo tradicional podem criar dificuldades no início, e isso pode frustrar as expectativas iniciais dos docentes.

No projeto relatado neste artigo, havia a expectativa (de todos os professores envolvidos e coordenação) de que os alunos respondessem ao questionário inicial para embasar possíveis ações para motivar ou mesmo para redirecionar os encaminhamentos das disciplinas em questão. Entretanto, menos de $10 \%$ dos matriculados forneceram a resposta solicitada. Mas, se o 
estudante não (ou pouco) colabora com a discussão e planejamento de alternativas eficazes para resolver (ou ao menos minimizar) a questão da retenção e vagas nas disciplinas em análise, o que resta a fazer, se não a discussão entre os pares?

Responderam ao questionário final utilizado para a realização da pesquisa 154 (cento e cinquenta e quatro) alunos da disciplina de Cálculo Diferencial e Integral 1 e 71 (setenta e um) alunos da disciplina de e Geometria Analítica e Álgebra Linear, totalizando 225 (duzentos e vinte e cinco) participantes do primeiro e segundo semestres letivos de 2014.

Os estudantes foram questionados do porquê da escolha da modalidade a distância para cursarem as disciplinas de CDI I e GAAL; cerca de 49\% dos respondentes, matriculados na disciplina de Geometria Analítica e Álgebra Linear, optaram por fazer a disciplina na modalidade a distância por encontrarem dificuldades em encaixar a disciplina na grade do curso. Já $40 \%$ dos respondentes da disciplina de Cálculo Diferencial Integral I, informaram ter escolhido a modalidade a distância devido à maior flexibilidade nos horários de estudo, como pode ser visto na Figura 1.

Figura 1. Escolha da modalidade a distância

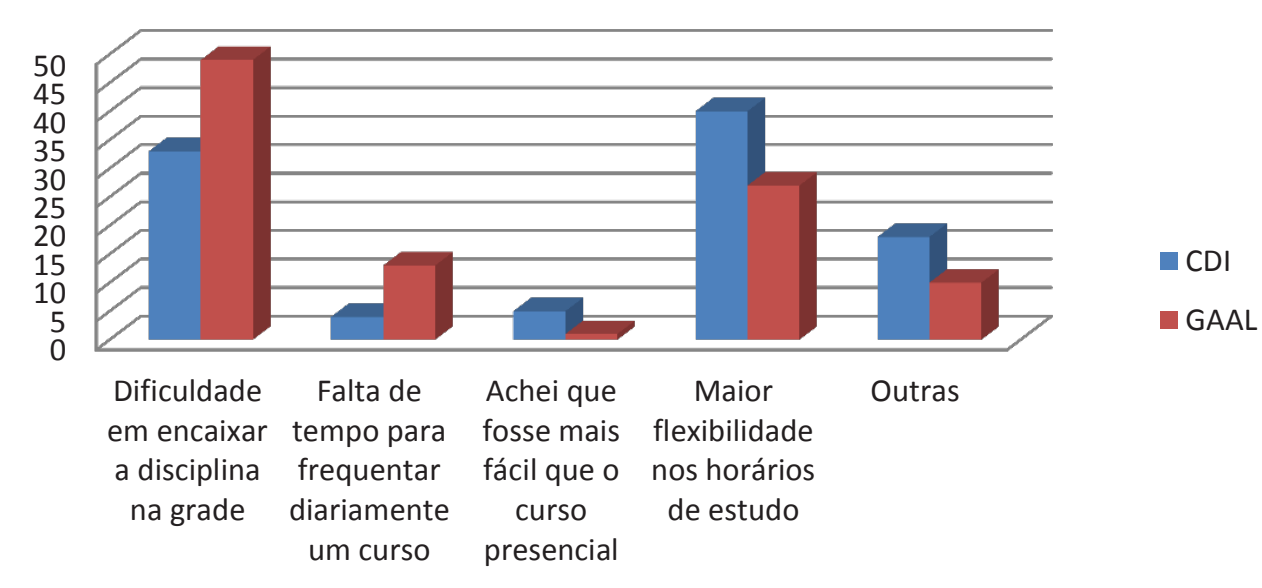

Fonte: Elaborada pelos autores.

É importante destacar que, conforme a Figura 1, os maiores índices para a escolha da modalidade referem-se à flexibilização de horários de estudo. Entretanto, há que se ressaltar que a EaD exige maior comprometimento e organização. Rurato (2008, p. 24) ressalta: "Ao escolher estudar a distância, estes aprendentes devem manter um elevado grau de motivação, sendo-lhes, igualmente, exigido um maior grau de independência, com uma interacção limitada, muitas vezes dependendo da sua iniciativa".

Especificamente nesse caso, uma reflexão é bastante pertinente: nossos graduandos estão preparados para a independência necessária na EaD? Responder essa pergunta é crucial para todos aqueles que pretendem enredar-se na organização de cursos a distância, especialmente porque terão que lidar com variáveis qualitativas como o interesse e a organização do aluno. 
Importa refletir, quando da organização de um curso EaD, em como promover o estímulo necessário para que ele seja eficaz.

Nessa tentativa de conhecer um pouco melhor o alunado, os estudantes ainda foram inqueridos sobre qual modalidade de ensino tiveram maior aproveitamento/aprendizagem no decorrer da disciplina. Vale lembrar que as disciplinas de GAAL e CDI I foram ofertadas apenas a alunos já repetentes. 37\% dos estudantes das disciplinas de GAAL e CDI I afirmaram que o maior aproveitamento foi com a EaD, já 34\% dos alunos de GAAL e 32\% dos estudantes de CDI I informaram que tiveram maior aprendizado na modalidade presencial; e $29 \%$ dos discentes de GAAL e 31\% de CDI I declararam que o aproveitamento que tiveram foi igualmente na presencial quanto na EaD.

O fato de cerca de $1 / 3$ dos estudantes respondentes relatarem maior aprendizado na $\mathrm{EaD}$ pode indicar uma mudança no perfil de aceitação dos cursos dessa modalidade, e, consequentemente, no aceite da sua responsabilidade na sua própria aprendizagem. Reportando-se a outros autores, Rurato (2008) afirma que a mudança pedagógica que ocorreu na educação a distância resultou da alteração de um modelo baseado na transmissão de conhecimentos, para um modelo construtivista, sócio-cultural e metacognitivo. Estes modelos utilizam como forma de comunicação privilegiada o computador, e dão ênfase à responsabilidade dos aprendentes, pela sua própria aprendizagem.

Ainda nesse sentido, é importante ressaltar que um maior aproveitamento das disciplinas na modalidade a distância pode ser devido ao fato do estudante poder seguir sua própria rotina de estudos, com horários flexíveis, facilitando e possibilitando, em muitos casos, cursar outras disciplinas presenciais, conforme as grades dos cursos. Mas é importante ressaltar mais uma vez que, para obter sucesso nas disciplinas, os estudantes precisam de autodisciplina, motivação, organização, compromisso e dedicação. Meneghetti e Redling (2012) consideram que uma importante contribuição para aprender significativamente está no fato de o aluno perceber-se como autogestor de sua própria formação. Rezende e Dias (2010) afirmam que as modalidades à distância e presencial podem enriquecer-se conjuntamente e ressaltam a necessidade de melhorar a qualidade de ambas, que coexistem nos dias de hoje.

Os alunos foram perguntados sobre como se organizam antes de estudar: $26 \%$ dos estudantes de GAAL e 11\% de CDI 1 responderam que priorizam e selecionam os conteúdos em que têm mais facilidade para estudar; 47\% dos discentes de GAAL e 63\% de CDI I declararam que verificam os conteúdos e procuram selecionar o que tem mais dificuldade. Já $27 \%$ dos alunos de GAAL e 26\% de CDI 1 afirmam que procuram fazer um plano de estudos e um cronograma para cumprir. Nesse aspecto, ainda observa-se a necessidade de maior aprimoramento quanto ao método de estudo, por parte dos estudantes, já que apenas cerca de $1 / 4$ dos respondentes afirmam elaborar um plano de estudos, o que viabiliza uma maior integração dos diversos conteúdos estudados ao longo das disciplinas.

Ainda nesse sentido, os alunos foram questionados sobre quando acessam a internet para estudar: 32\% dos estudantes de CDI I e 42\% de GAAL afirmaram que procuram se ater apenas às páginas relativas aos conteúdos; já 57\% dos estudantes de CDI I e 48\% de GAAL declararam que até entram em sites de relacionamento, mas não deixam de estudar por causa disso. E 10\% dos estudantes de GAAL e 11\% de CDI I informaram que quando acessam a internet para estudar acabam se dispersando com sites de relacionamento e afins. 
Com base nestas informações, foi possível observar que os estudantes procuram selecionar os conteúdos que têm maior dificuldade em adquirir conhecimento, porém, ao acessar a internet para estudar acabam acessando, também, sites de relacionamento. Sendo assim, os discentes não conseguem se ater aos conteúdos de maneira efetiva, ocasionando um menor rendimento nas atividades propostas nas disciplinas e, em alguns casos, até mesmo a desistência e a reprovação.

Questionados sobre o tempo que reservam para estudar as disciplinas em EaD, 61\% dos estudantes da disciplina de Geometria Analítica e Álgebra Linear responderam que procuram estudar os conteúdos conforme as datas previstas de provas e entrega de trabalhos. Já, $28 \%$ dos alunos da disciplina de Cálculo Diferencial Integral I, informaram que estabelecem um cronograma, com rotina diária ou semanal para estudos referente à disciplina, como pode ser visto na Figura 2. É importante destacar que ambas as disciplinas requerem conhecimentos prévios, por vezes mais elaborados, e que precisam de maior amadurecimento para sua devida compreensão. Estudar apenas próximo às datas das avaliações pode não permitir o acesso ao conhecimento e às articulações necessárias para obter sucesso nas respectivas avaliações.

Figura 2. Organização dos estudos em EaD

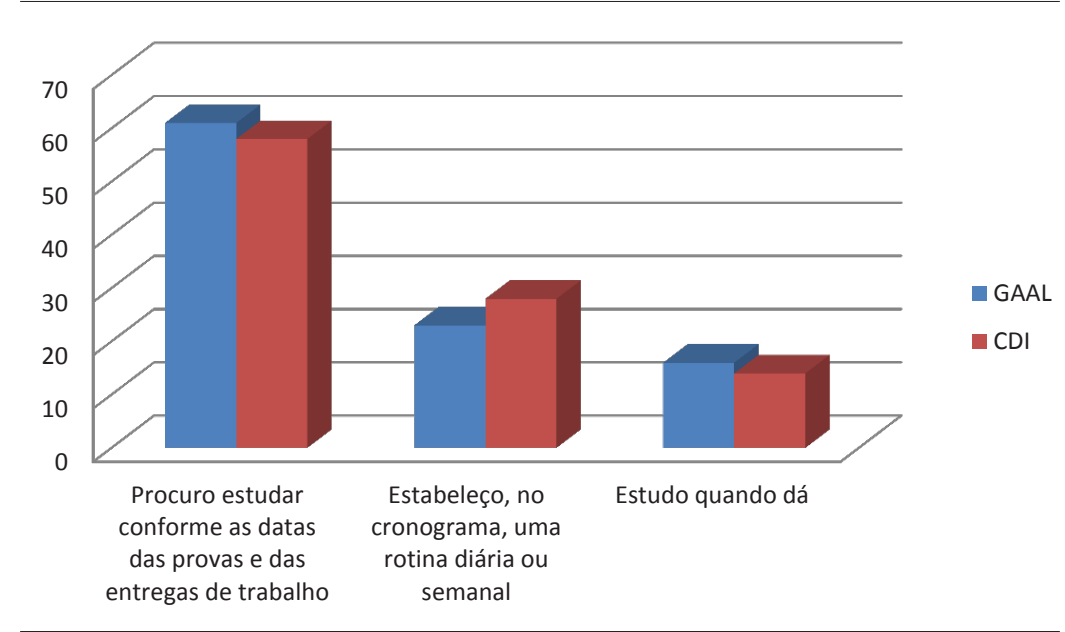

Fonte: Elaborada pelos autores.

Sendo assim, é importante ressaltar que menos de 30\% dos estudantes das disciplinas estabelecem uma rotina diária de estudo, enquanto uma média de 15\% estudam "apenas quando dá" mostrando que a modalidade a Distância não tem sido considerada por esses alunos como uma alternativa de ensino. Além disso, é possível observar que estudantes encontram dificuldades em incorporar essa modalidade à sua realidade, pelo fato de estarem acostumados com o ensino presencial, onde o professor é o detentor do conhecimento, levando as informações "prontas". Já na EaD, o professor se torna mediador da aprendizagem e muitos alunos têm dificuldades em buscar a construção do seu próprio conhecimento. De acordo com Rurato (2008, p. 26): 
O conceito de aprendente autónomo ou independente, capaz de auto-gestão dos seus estudos, é ainda embrionário, do mesmo modo que o estudante autónomo é, ainda, uma excepção no universo do ensino, seja convencional ou não. A única certeza, talvez seja a convicção de que a educação, em geral, e o ensino, em particular, se devem transformar, de modo a permitir dar condições e encorajar uma aprendizagem autónoma, que propicie e promova a construção do conhecimento.

Um mecanismo utilizado para orientar os estudantes a como estudar na modalidade $\mathrm{EaD}$ foi o depoimento, nos encontros presenciais de instrução (onde indicavam-se os meios de acesso ao material e esclarecimento de dúvidas, entre outras coisas), de alunos que haviam sido aprovados. Esses depoentes falavam sobre sua experiência no estudo na modalidade EaD, especialmente em relação à carga horária disponibilizada a esse estudo. A partir disso, notouse que os alunos começaram a se dedicar um pouco mais, porque começaram a vislumbrar a possibilidade de aprendizagem autônoma, porém orientada pelos monitores e professores.

Mercado (2007) ainda argumenta que é necessário que exista autonomia dos alunos em relação a organização do tempo de estudo, emprego dos recursos, espaços e participação. Tanto a flexibilização das aprendizagens como a autonomia do estudante fará com que o aluno se mova entre o estrito acompanhamento das instruções e pautas de condutas marcadas pelos materiais curriculares e a autoinstrução. Os princípios de flexibilização e autonomia têm de possibilitar ao aluno o acompanhamento de forma individualizada, itinerários de leitura dos materiais curriculares e de estudo, a ordem da realização das atividades, a escolha de atividades alternativas e, enfim, deverá facilitar e conseguir os objetivos formativos pretendidos.

Com relação ao esclarecimento de dúvidas, cerca de $72 \%$ dos estudantes de GAAL e $81 \%$ dos alunos de CDI 1 responderam que pesquisam prováveis respostas e, sempre que possível, procuram o monitor ou o professor para ajudar a esclarecer as dúvidas. Já para $22 \%$ dos discentes de GAAL e $12 \%$ de CDI I informaram que deixam as dúvidas de lado, e passam a estudar outros assuntos referentes à disciplina; e apenas $6 \%$ dos alunos de GAAL e 7\% de CDI I, esperam até o monitor ou o professor estar disponível para responder as dúvidas. Novamente, cabe uma reflexão sobre a contribuição das prováveis respostas em detrimento do porquê de tais procedimentos para obtê-las. Será que esses graduandos sabem estudar ou apenas estão procurando respostas prontas? Em que medida essas procuras contribuem para a compreensão dos conceitos básicos das duas disciplinas em discussão?

Com relação aos momentos de atendimento aos alunos, quer seja on-line ou presencial, com o professor ou monitores, o mesmo é subutilizado, ou seja, um número muito pequeno de estudantes procura por este tipo de auxílio e, os que procuram, são sempre os mesmos. Contudo, esses discentes têm obtido maior êxito nas avaliações.

Ainda nesse sentido, foram questionados sobre o volume de tarefas (listas e questionários) disponibilizado em cada módulo, 61\% dos estudantes de CDI I e 55\% dos estudantes de GAAL informaram que a quantidade de tarefas é adequada com a rotina de atividades; $12 \%$ dos estudantes de GAAL e CDI I responderam que o número de atividades é muito elevado. Para 30\% de discentes de GAAL e 23\% de CDI I, as listas e questionários são elevados para o tempo estipulado para a entrega; já para 3\% dos estudantes de CDI I e GAAL, as atividades 
são insuficientes; e para 1\% dos estudantes de CDI 1 o volume de tarefas disponibilizado em cada módulo é muito insuficiente.

Ainda sobre a participação dos estudantes nas atividades de entrega de lista de exercícios e questionários on-line, há uma crescente queda na quantidade de alunos que realizam essas atividades. O que se nota é que alguns alunos procuram "apostar todas as fichas" nas avaliações; outros começam a "copiar" listas de colegas e, à medida em que "são pegos" na correção, acabam desistindo destas atividades. Ao final do período letivo, o número de estudantes assíduos a estas atividades se equipara ao que realiza a última avaliação e, em alguns câmpus, este percentual chega a $20 \%, 15 \%$ e até $10 \%$ dos alunos ingressantes.

Entre as mudanças ocorridas para evitar essa evasão está o número de exercícios que deveriam ser entregues semanalmente. Passou-se de 10 (dez) para 5 (exercícios). Isso porque percebeu-se que resolver os exercícios, escanear e inserir no MOODLE, além de estudar todo o material referente ao conteúdo e responder ao questionário on-line (com dez questões de múltipla escolha) eram atividades que estavam sobrecarregando os alunos, pois, em geral, todos cursavam entre 8 (oito) e 10 (dez) disciplinas regulares. Apesar dessa redução na quantidade de exercícios a entregar, aumentou-se a quantidade de exercícios indicados, inclusive de outros livros indicados nos planos de ensino das referidas disciplinas.

Outra questão tratava da avaliação que fazem sobre o seu próprio desenvolvimento da capacidade de autonomia e de auto-organização (tempo) durante o transcorrer da disciplina. 43\% dos estudantes de GAAL informaram que avaliam como bom a sua capacidade de autonomia; já 41\% dos alunos de CDI I responderam que avaliam como regular a capacidade de autonomia e de auto-organização durante o transcorrer da disciplina, como pode ser visto na Figura 3. Analisando estes dados em conjunto com as aprovações, verifica-se que, embora parte dos alunos se avaliem de maneira positiva quanto à capacidade de autonomia e auto-organização, este resultado não se reflete na realização das atividades on-line e tampouco nas avaliações. Em parte, isso pode ser devido ao modo de estudo do estudante, que envolve mais leitura de materiais, visualização de vídeo-aulas e realização dos exercícios propostos.

De acordo com Salbego e Tumolo (2014), a autonomia é ainda mais importante quando o contexto de aprendizagem é a EaD. Pelo fato de que os docentes não representam mais o papel central no processo de ensino e aprendizagem dos discentes, desta maneira, estes precisam apresentar mais responsabilidade pelo seu próprio desenvolvimento. Consequentemente, a autonomia se torna um fator central, pois consiste numa forma de auxiliar os estudantes a decidir quais estratégias e abordagens de estudo realmente os auxiliam na aprendizagem, de acordo com as suas particularidades.

Os alunos foram inqueridos sobre a compatibilidade da avaliação de aprendizagem com o conteúdo trabalhado. Mais de 50\% dos respondentes atestaram haver compatibilidade entre o conteúdo disponibilizado no AVEA e a avaliação regimental. Outros 30\% dos estudantes de CDI I e $25 \%$ de GAAL declararam que concordam em partes, que há compatibilidade da avaliação nas disciplinas; já 13\% dos alunos de GAAL e 12\% de CDI I afirmaram que discordam que o conteúdo trabalhado é compatível com a aprendizagem adquirida ao longo da disciplina. E, além destes, 7\% dos estudantes de CDI I e 9\% de GAAL declararam que discordam completamente que tenha alguma compatibilidade entre a avaliação de aprendizagem com o conteúdo disponibilizado ao longo da disciplina. 
Fornari, A.; Cargnin, C.; Gasparin, P. P.; Araújo, E. C.

Figura 3. Avaliação de autonomia

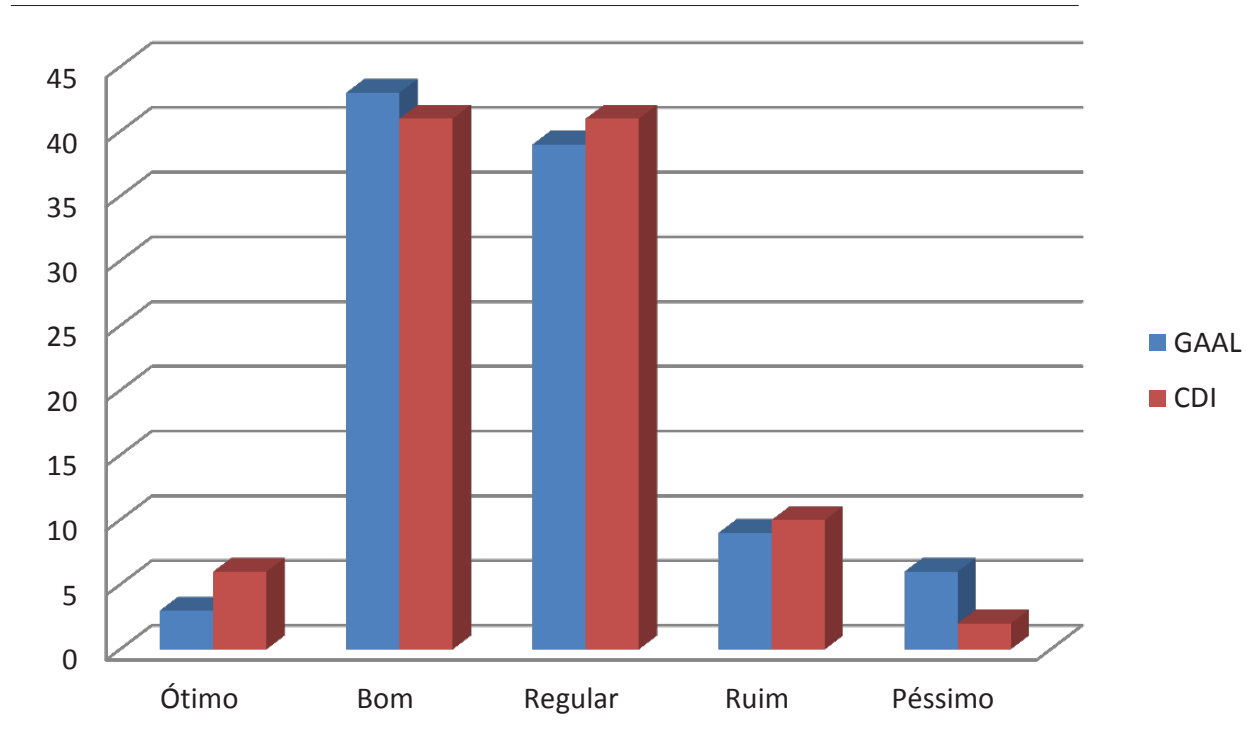

Fonte: Elaborada pelos autores.

Nesse sentido, os professores foram orientados a verificar o material disponibilizado aos alunos antes de elaborar suas provas regimentais. Um problema constatado foi que nem todos os docentes tinham conhecimento sobre a abordagem adotada no material, já que foram inseridos depois de iniciado todo o processo de planejamento e elaboração do conteúdo.

Com relação à qualidade do material, cerca de 35\% dos estudantes de ambas as disciplinas afirmam ser de boa qualidade. Entretanto, cerca de $24 \%$ ressaltam a necessidade de melhoria do conteúdo abordado em GAAL, como pode ser visto na Figura 4. Em relação a isso, foram gravadas mais vídeo-aulas, especialmente para os tópicos considerados de maior dificuldade como espaço vetorial. Também foi revisto todo o conteúdo escrito, aumentando a quantidade e variedade de exemplos, resolvidos detalhadamente.

Em relação a estes dois últimos pontos mensurados, muitos alunos matriculados nas disciplinas em EaD deixam de acessar o conteúdo disponibilizado na plataforma. Alguns, inclusive, nem sequer começam o estudo com base no material disponibilizado. Este comportamento se dá pelo fato de procurarem se embasar em conteúdos vistos quando cursaram presencialmente a disciplina. Outro ponto identificado é o "estudo em grupo", com base em listas de exercícios também já vistas. Ainda é pequeno o número de estudantes que efetivamente estudam todo o material disponibilizado pela plataforma. Na tentativa de reverter esse quadro, professores e monitores foram orientados a manterem contato, pelos meios disponíveis na plataforma MOODLE (fóruns e mensagens), com os alunos, incentivando-os ao estudo e comunicando sobre as datas de entrega de material avaliativo. 
Figura 4. Avaliação do material didático

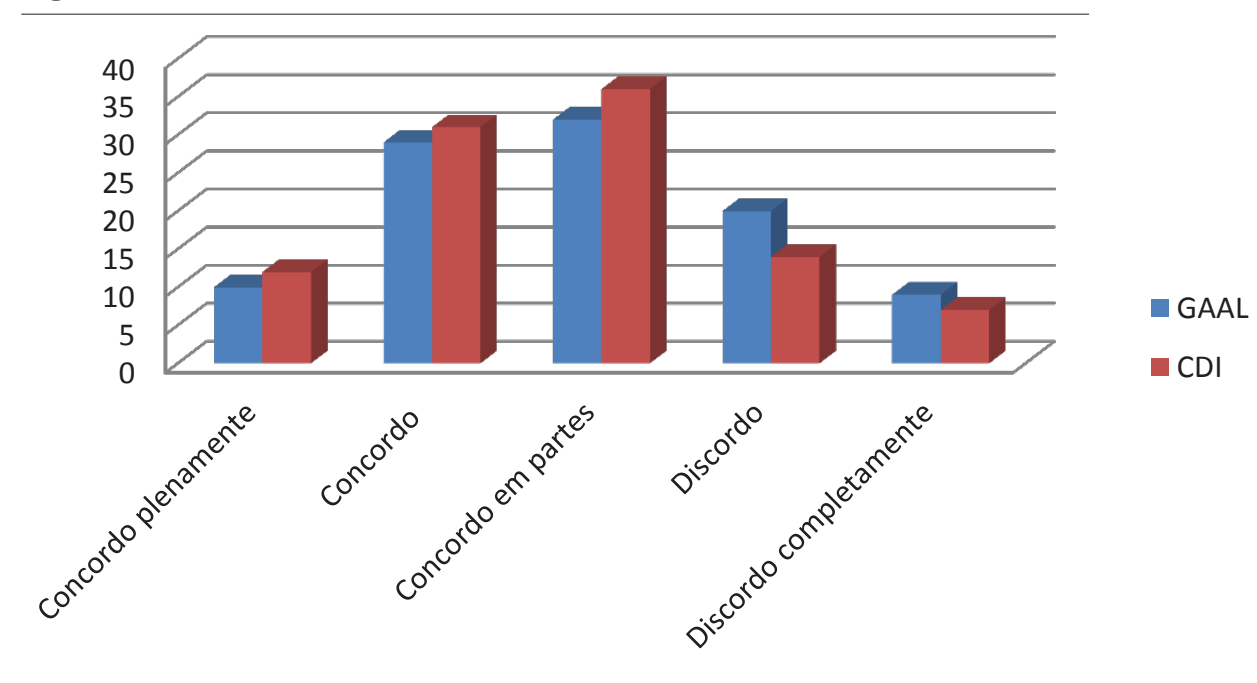

Fonte: Elaborada pelos autores.

Os alunos foram questionados sobre os horários de monitoria presencial, se são suficientes para esclarecer as suas dúvidas: $12 \%$ dos estudantes de CDI I e 16\% dos estudantes de GAAL informaram que concordam plenamente que a monitoria é suficiente para esclarecer as dúvidas; já 36\% dos alunos de GAAL e 43\% de CDI I responderam que concordam que a monitoria presencial é satisfatória para esclarecer todas as dúvidas. $26 \%$ dos estudantes de CDI I e $21 \%$ de GAAL declararam que concordam em partes que a monitoria seja suficiente para esclarecer as dúvidas, ao passo que 19\% dos alunos de GAAL e 16\% de CDI I afirmaram que discordam que os horários de monitoria são suficientes. E 3\% dos estudantes de CDI I e $8 \%$ de GAAL declararam que discordam completamente que o tempo disponibilizado para a monitoria presencial consiga sanar as dúvidas.

Os estudantes dispõem de até 23 horas de atendimento semanal pelo professor e por 3 monitores com 15 horas por semana cada um para atendimento presencial e on-line. Infelizmente, o que se pode inferir é que a monitoria ocorre passivamente. Os alunos buscam apenas a resolução dos exercícios propostos em vez de subsídios para fortalecer o processo de aprendizagem.

Ainda foram inqueridos sobre as principais dificuldades que encontraram na comunicação entre o professor/monitor/aluno. Dentre os estudantes de GAAL, 63\% informaram que não encontraram dificuldades na comunicação pelo fato de professores e monitores sempre responderem aos questionamentos. Um dos estudantes relatou que não encontrou dificuldades, pois os monitores e o professor possuíam horários disponíveis para o atendimento presencial e que, além disso, possuíam horários de atendimento virtual, tornando fácil encontrá-los no câmpus e sanar todas as dúvidas. Por outro lado, 37\% dos alunos de GAAL encontraram algum tipo de dificuldade, dentre elas, destacaram: a demora em responder os questionamentos via ambiente MOODLE; dificuldades em conciliar os horários de monitoria presencial, já que 
em muitos casos os horários de monitoria coincidiam com os horários das demais disciplinas presenciais; e alguns monitores com dificuldades em esclarecer as dúvidas dos alunos.

Como parte de mudança na metodologia de ensino, o estudante ainda não se acostumou com as atividades assíncronas, onde a resposta pode ocorrer em tempo diferente à questão. $\mathrm{O}$ tempo de resposta para questionamentos, por parte dos professores e monitores, não ultrapassa 24 horas. Contudo, para minimizar os confrontos de horário entre a monitoria e demais aulas, foi indicado alocar a monitoria nos horários de intervalos entre os períodos, como o final da tarde ou horários noturnos, já que a maioria dos estudantes desses cursos na modalidade EaD são do período diurno.

Com relação ao despreparo de monitores para resolução da lista de exercício, um dos discentes relatou que alguns monitores não conseguem resolver as listas de exercícios propostas e, por isso, os estudantes que têm dificuldades e recorrem aos monitores acabam prejudicados. Esse fato nos indica a necessidade de professor e monitor discutirem previamente todo o material disponibilizado aos alunos, inclusive as listas. Discussão essa que poderá contribuir com um atendimento mais adequado às necessidades e dificuldades docentes.

Já outro aluno sugere ao professor que prepara as provas, que pondere o nível de dificuldade dos exercícios disponibilizados no ambiente virtual e prepare a prova com o mesmo grau de dificuldade. Essa ainda é uma situação complexa porque requer do professor a superação de desafios, tal como expõem Gasparin, Cargnin e Araújo (2015, p. 8):

Preparar exercícios para as listas, que estivessem de acordo com o conteúdo do material, muitas vezes preparado por outro docente, com outra visão, tornou-se um desafio. Em vários momentos, foi preciso deixar de lado sua própria perspectiva de ensino para compreender a visão do outro. Ainda há vários acertos a serem feitos nesse ponto.

Os alunos de Cálculo Diferencial Integral I também foram questionados sobre as principais dificuldades que encontraram na comunicação entre o professor/monitor/aluno: $44 \%$ dos estudantes afirmaram não terem encontrado dificuldades, pois sempre que surgiram dúvidas, tanto os professores quanto os monitores as esclareceram. Nesse sentido, um dos discentes argumentou: "não houve dificuldades encontradas por mim em relação aos monitores e o professor, ficou claro desde o início como iria e como deveria ser desde o início do semestre, o professor sempre esteve presente nos horários de atendimento, e os monitores trabalharam duro para que pudessem ajudar da melhor forma possivel."

Já 17\% dos estudantes de CDI I resolveram dar sugestões para melhorar a comunicação entre professor/monitor/aluno, entre as sugestões, destacam-se: comunicação entre professor/ monitor/aluno por meio de vídeo; horários de monitoria mais flexíveis; mensagens instantâneas para esclarecimento de dúvidas na plataforma; maior número de monitorias presenciais.

Ainda nesse sentido, um dos estudantes relatou: "muito ruim o sistema de comunicaşão, muito pouco interativo, deveria ser algo semelhante a um "chat" com suporte a câmera e envio rápido e fácil de imagens. Ou mesmo um local onde se pode 'desenhar' o exercicio, semelhante ao Paint e enviar para monitor/ professorpara que possa ser respondido da mesma maneira”. Esta sugestão de maior interação faz parte do planejamento para o ano 2016, em que um plugin do MOODLE, chamado Big Blue Button, fará parte da plataforma, propiciando interação com áudio, imagem e vídeo. 
Porta (2014, p. 20) argumenta que "[...] a utilização de um software como ferramenta no ensino e aprendizagem, em geral, proporcionam a interatividade e a possibilidade do aluno construir seus próprios objetos, permitindo a compreensão de conceitos mesmo quando abstratos".

Por outro lado, $39 \%$ dos discentes informaram ter encontrado dificuldades na comunicação, entre elas estão: poucos horários de atendimento presencial do professor e do monitor; demora em responder aos questionamentos via plataforma; pouco contato virtual entre professor/aluno/monitor; dificuldade em conciliar horário de monitoria com as aulas presenciais. Provas de maior grau de dificuldade que as listas de exercícios e materiais disponíveis no ambiente virtual de ensino e aprendizagem.

Ainda nesse sentido, para um dos estudantes, a dificuldade se apresenta quando o monitor e o professor não apresentam boa explicação em relação às dúvidas, sendo que muitas vezes as respostas do monitor e do professor fazem surgir mais dúvidas. Esse conflito está sendo resolvido com reuniões semanais entre professores e monitores para discutirem as listas de exercícios propostas, bem como o conteúdo disponibilizado. Essas reuniões têm contribuído para uma efetiva melhoria no conteúdo e maior consenso entre as possíveis dificuldades de explicação e de compreensão de enunciados.

\section{Considerações finais}

É importante salientar que o projeto de ofertar as disciplinas de Cálculo Diferencial Integral I e Geometria Analítica e Álgebra Linear pela modalidade a distância foi criado em 2013, pela Pró-Reitoria de Graduação da UTFPR, e foi implantado em 2014, devido à grande demanda de alunos reprovados e que não conseguiam vagas em turmas presenciais e especiais.

Nesta pesquisa foi possível identificar que a maioria dos estudantes que se inscreveram para realizar as disciplinas pela modalidade $\mathrm{EaD}$, fizeram essa opção devido à dificuldade em encaixar a disciplina na grade de horário de suas aulas e à maior flexibilidade nos horários de estudo. Além disso, os estudantes pareceram estar cientes de que a EaD exige autodisciplina, responsabilidade e motivação, devido ao fato de o professor não ser mais o detentor do conhecimento, e sim, o mediador; desta maneira, precisam se organizar e buscar construir o seu próprio conhecimento, mas encontram dificuldades em se adaptar às novas exigências por, talvez, não ser esta uma atitude exigida no ambiente escolar até ao nível médio, ou ainda, pela linguagem demasiadamente técnica utilizada nos livros didáticos.

Por outro lado, é importante destacar também que a pesquisa indicou que os estudantes, ao ingressarem no ensino superior, acabam se deparando com uma nova realidade, encontrando muitos empecilhos principalmente nas disciplinas de CDI I e GAAL, devido à defasagem dos conteúdos em matemática básica, que é apontada por diversas pesquisas como um dos obstáculos que causam grande índice de reprovação e desistência pelo fato dos alunos apresentarem baixo desempenho nas disciplinas. (GASPARIN et al., 2014).

Evidenciou-se que os estudantes, ao acessarem a internet para estudar, acabam acessando, ao mesmo tempo, sites de redes sociais, o que diminui a atenção dada à disciplina em estudo. Ainda é importante ressaltar que são poucos os alunos que estabelecem uma rotina diária de estudos, apenas estudam "quando dá", indicando que a EaD não tem sido considerada por esses alunos como uma alternativa de ensino. 
É importante destacar que o presente texto é um estudo exploratório, em que foram levantadas questões sobre a EaD como alternativa para disciplinas em que há muitos estudantes reprovados na modalidade presencial, que precisam ser mais bem exploradas em trabalhos futuros. Entretanto, os resultados obtidos indicam que se deve enfatizar a necessidade de maior conscientização dos alunos quanto às exigências fundamentais para fazer um curso na modalidade EaD: organização, disciplina e motivação. Por outro lado, como ressaltam Gasparin, Cargnin e Araújo (2015), é preciso, também, que o professor aceite o desafio de ensinar a distância, que não ocupam o papel central no processo de ensino e aprendizagem, mas que devem atuar como orientadores e mediadores desse processo.

\section{Referências}

AGUIAR, M. J. G. et al. Aproximação de métodos qualitativos e quantitativos na pesquisa em saúde. In: SIMPÓSIO INTERNACIONAL DE CIÊNCIAS INTEGRADAS DA UNAERP, [2013], Guarujá. Disponível em: <http://www.unaerp.br/documentos/1568--31/ file>. Acesso em: 09 dez. 2015.

ALMEIDA, L. M. W.; FATORI, L. H.; SOUZA, L. G. S. Ensino de cálculo: uma abordagem usando a modelagem matemática. Revista Ciência e Tecnologia, Campinas, v. 10, n. 16, p. 47-59, 2007. Disponível em: <http://www.revista.unisal.br/sj/index.php/123/article/ view/17/31>. Acesso em: 13 dez. 2015.

DALFOVO, A. F. et al. UAB: avanços e desafios na percepção de docentes. Revista Paidei@, Santos, v. 7, n. 12, p. 1-19, 2015. Disponível em: < http:// revista paideia. unimesvirtual.com.br/index.php?journal $=$ paideia\&page $=$ article\&op $=$ view $\&$ path[ =409\&path $\rrbracket=459>$. Acesso em: 06 dez. 2015.

GARCIA, L. F. U.; DIRENE, A. Metodologia para implementação de estratégias colaborativas mediadas por ferramentas de interação síncrona. Tecnologias, Sociedade e Conhecimento, Campinas, v. 1, n. 1, 2013. Disponível em: <http://www.nied.unicamp.br/ ojs/index.php/tsc/article/view/111/99>. Acesso em: 09 dez. 2015.

GASPARIN, P. P.; CARGNIN, C.; ARAÚJO, E. C. O papel do professor na disciplina de cálculo diferencial e integral I em uma plataforma AVA na UTFPR. In: SIMPÓSIO INTERNACIONAL SOBRE DESENVOLVIMENTO PROFISSIONAL DOCENTE, 2. 2015, Curitiba. Anais... Curitiba: UTFPR, 2015. 1 CD-ROM.

GASPARIN, P. P. et al. O impacto do cálculo diferencial e integral nos alunos ingressantes dos cursos de engenharia. In: ENGENHARIA: múltiplos saberes e atuações. Juiz de Fora: Cobenge, 2014. Disponível em: <http://www.abenge.org.br/cobenge-2014/Artigos/129796. pdf>. Acesso em: 07 dez. 2015

GIL, A. C. Como elaborar projetos de pesquisa. 4. ed. São Paulo: Atlas, 2002. . 6. ed. São Paulo: Atlas, 2008. 
Cálculo Diferencial e Integral e Geometria Analítica e Álgebra Linear ...

IVASHITA, S. B.; COELHO, M. P. EaD: o importante papel do professor-tutor. In: CONGRESSO NACIONAL DE EDUCAÇÃO - EDUCERE, 9., [e] ENCONTRO SUL BRASILEIRO DE PSICOPEDAGOGIA, 3., 2009, Curitiba. Anais... Disponível em: $<$ http://www.pucpr.br/eventos/educere/educere2009/anais/pdf/2865_1873.pdf>. Acesso em: 09 dez. 2015.

LAKATOS, E. M.; MARCONI, M. A. Fundamentos de metodologia científica.5. ed. São Paulo: Atlas, 2003.

MENEGHETTI, R. C. G.; REDLING, J. P. Tarefas alternativas para o ensino e a aprendizagem de funções: análise de uma intervenção no ensino médio. Bolema, Rio Claro, v. 26, n. 42A, p. 193-230, 2012. Disponível em: <http://dx.doi.org/10.1590/S0103636X2012000100010>. Acesso em: 18 dez. 2015.

MERCADO, L. P. L. Dificuldades na educação a distância online. In: CONGRESSO INTERNACIONAL DE EDUCAÇÃO A DISTÂNCIA, 13., 2007, Curitiba. Anais... Curitiba: ABED, 2007. Disponível em: <http://www.abed.org.br/congresso2007/ tc/55200761718PM.pdf>. Acesso em: 14 dez. 2015.

MORESI, E. (Org.). Metodologia da pesquisa. Brasília: Universidade Católica de Brasília, 2003.

MORÉ, R. P. O. et al. Ambiente virtual de ensino-aprendizagem: relato de experiência com curso de ciências da administração a distância da UFSC. In: COLOQUIO INTERNACIONAL SOBRE GESTIÓN UNIVERSITARIA EM AMÉRICA DEL SUR, 10., 2010, Mar del Plata. Disponível em: < https:// repositorio.ufsc.br/ handle/123456789/96894>. Acesso em: 6 nov. 2015.

MUGNOL, M. A educação a distância no Brasil: conceitos e fundamentos. Revista Diálogo Educacional, Curitiba, v. 9, n. 27, p. 335-349, 2009. Disponível em: <http://www.redalyc. org/articulo.oa?id=189117298008>. Acesso em: 8 dez. 2015.

PALIS, G. R. A transição do ensino médio para o ensino superior. In: ENCONTRO NACIONAL DE EDUCAÇÃO MATEMÁTICA, 10., 2010, Salvador. Disponível em: < http://www.lematec.net.br/CDS/ENEM10/artigos/PA/Palestra4.pdf > . Acesso em: 12 dez. 2015.

PORTA, L. D. Contribuições da engenharia didática para o ensino e aprendizagem de funções de várias variáveis reais. 2014. Dissertação (Mestrado Profissionalizante em Ensino de Física e de Matemática) - Centro Universitário Franciscano, Santa Maria, 2014.

REZENDE, W. M.; DIAS, A. I. A. S. Educação a distância e ensino presencial: incompatibilidade ou convergência? EAD em Foco, Rio de Janeiro, n. 1, v. 1, p. 7-16, 2010. Disponível em: <http://eademfoco.cecierj.edu.br/index.php/Revista/article/ viewFile/10/1>. Acesso em: 14 dez. 2015.

RICCIO, N. C. R. Ambientes virtuais de aprendizagem na UFBa: a autonomia como possibilidade. 2010. 363 f. Tese (Doutorado em Educação) - Universidade Federal da Bahia, Salvador, 2010. Disponível em: <http://repositorio.ufba.br/ri/handle/ri/14230>. Acesso em: 6 dez. 2015. 
Fornari, A.; Cargnin, C.; Gasparin, P. P.; Araújo, E. C.

ROSA, M; OREY, D. C. O construtivismo como um embasamento teórico-filosófico para o ambiente virtual Moodle de aprendizagem. In: CONGRESSO BRASILEIRO DE ENSINO SUPERIOR A DISTÂNCIA, 10., 2013, Belém. Anais... Belém: ESUD, 2013. 1 CD-ROM.

RURATO, P. A. L. As características dos aprendentes na educação a distância: impacto no processo educativo com vista ao desenvolvimento de estratégias de sucesso. 2008. $454 \mathrm{f}$. Tese (Doutorado em Gestão Industrial) - Universidade do Aveiro, [Braga], 2008. Disponível em: <https://ria.ua.pt/bitstream/10773/1843/1/2008000903.pdf >. Acesso em: 5 dez. 2015.

SANTOS, R. M.; BORGES NETO, H. Avaliação do desempenho no processo de ensino-aprendizagem de cálculo diferencial e integral I (o caso da UFC). [1993]. Disponível em: < http://www.multimeios.ufc.br/arquivos/pc/artigos/artigo-avaliacao-dodesempenho-no-processo-de-ensino-aprendizagem.pdf>. Acesso em: 9 dez. 2015.

SALBEGO, N. N; TUMOLO, C. H. S. Autonomia na aprendizagem de línguas em EaD: percepção de alunos com relação ao desenvolvimento das quatro habilidades em inglês. In: CONGRESSO BRASILEIRO DE ENSINO SUPERIOR A DISTÂNCIA, 11., 2014, Florianópolis. Anais... Florianópolis: ESUD, 2014. p. 1820-1834. Disponível em: < http:// esud2014.nute.ufsc.br/anais-esud2014/files/pdf/126731.pdf>. Acesso em: 14 nov. 2015.

SILVA, B. A. Contrato didático. In: MACHADO, S. D. A. (Org.). Educação matemática: uma (nova) introdução. 3. ed. São Paulo: EDUC, 2008. p. 49-75.

TEIXEIRA, K. C. B.; PEREIRA, A. C. C. Os conhecimentos prévios de matemática trazidos pelos alunos ingressantes nos cursos de engenharias da Unifor: atual cenário. In: CONGRESSO BRASILEIRO DE EDUCAÇÃO EM ENGENHARIA, 40., 2012, Belém. Anais... Disponível em: <http://www.abenge.org.br/CobengeAnteriores/2012/ artigos/104080.pdf>. Acesso em: 9 nov. 2015.

WISLAND, B.; FREITAS, M. C. D.; ISHIDA, C. Y. Desempenho acadêmico dos alunos em curso de engenharia e licenciatura na disciplina de cálculo I. Revista Iberoamericana de Engenharia Industrial, Florianópolis, v. 6, n. 11, p. 94-112, 2014. Disponível em: < http:// incubadora.periodicos.ufsc.br/index.php/IJIE/article/view/3314>. Acesso em 13 nov. 2015

Artigo recebido em 31/01/2016. Aceito em 05/10/2016.

Endereço para contato: Rua Constantino Fabrício, 480, Madalozzo, CEP 85550-000, Coronel Vivida, PR, Brasil. 